\title{
Una discusión sobre el concepto de fosa clandestina y el contexto mexicano. El caso de Guanajuato
}

\section{A Discussion of the Concept of Clandestine Grave and the Mexican Context.}

The Case of Guanajuato

\author{
FABRIZIO LORUSSO \\ Universidad lberoamericana-León \\ México \\ Correo: fabrizio.lorusso@iberoleon.mx \\ https://orcid.org/0000-0003-1849-5323 \\ DOI: 10.48102/hyg.vi56.354
}

Artículo recibido: $1 / 07 / 2020$

Artículo aceptado: I 8/08/2020

\section{ABSTRACT}

The objective of the article is to present and discuss the concept of the clandestine grave, focusing on the Mexican context and the case of Guanajuato. An essential state of the art is constructed to account for the evolution in the use and meanings of the concept of the clandestine grave at the international level and especially in Mexico, in the context of the current human rights crisis and violence. With newspaper sources and official documents, the situation of clandestine graves in Guanajuato and the position of the State Prosecutor's Office in this regard are analyzed. Finally, a critical assessment is made of the legislative process of the Law for the Search of Missing Persons of the State of Guanajuato and of the proposal of definition of clandestine graves that, although it was not included in the Law, contributed to the public debate on this phenomenon and can be interpreted as part of a political and social dispute.

Key words: Clandestine Grave, Human Rights, Disappearance of People, Political Dispute, Guanajuato.

Historia y Grafia, Universidad Iberoamericana, año 28, núm. 56, enero-junio 2021, pp. I29- 170 


\section{RESUMEN}

El objetivo del artículo es presentar y discutir el concepto de fosa clandestina, aterrizándolo al contexto mexicano y al caso de Guanajuato. Se construye un estado del arte básico para dar cuenta de la evolución en el uso y en los significados del concepto de fosa clandestina a nivel internacional y especialmente en México, en el ámbito de la crisis de derechos humanos y de violencia actual. Con fuentes hemerográficas y documentos oficiales se analiza la situación de las fosas clandestinas en Guanajuato y la postura de la Fiscalía estatal al respecto. Por último, se hace un balance crítico del proceso legislativo de la Ley de Búsqueda de Personas Desaparecidas del Estado de Guanajuato y de las propuestas de definición de fosa clandestina que, aunque no fueron incluidas, contribuyeron al debate público sobre este fenómeno y se pueden interpretar como parte de una disputa política y social.

Palabras clave: fosa clandestina, derechos humanos, desaparición de personas, disputa política, Guanajuato.

\section{INTRODUCCIÓN ${ }^{1}$}

a categoría de "fosa clandestina" en México ha tenido cada vez
más presencia en los medios de comunicación, en el discurso de las autoridades, en la investigación académica y en las leyes durante la última década, en especial a partir del hallazgo de decenas

${ }^{1}$ Para la elaboración de este artículo y la discusión sobre las definiciones de fosa clandestina, agradezco los aportes de Grace Mahogany Fernández Morán (Consejo Nacional Ciudadano del Sistema Nacional de Búsqueda de Personas Desaparecidas, México); Jorge Ruiz Reyes (Programa en Derechos Humanos, Universidad Iberoamericana, Ciudad de México); Enrique Irazoque Palazuelos (Comisión Nacional de Búsqueda de Personas Desaparecidas, director general de Acciones de Búsqueda y Procesamiento de Información); Carolina Robledo Silvestre (Sistema Nacional de Investigadores, investigadora y profesora del Centro de Investigaciones y Estudios Superiores en Antropología Social, y fundadora del GIASF-Grupo de Investigaciones en Antropología Social y Forense); Natalia Pérez Cordero, Programa de Derechos Humanos y Lucha contra la Impunidad de Fundar (Centro de Análisis e Investigación, A. C.) y Edith López (onU-DH México). 
de entierros con restos humanos en los alrededores de la ciudad de Iguala, en Guerrero, durante las búsquedas de campo de los cuarentaitrés estudiantes de Ayotzinapa, víctimas de desaparición forzada la noche del 26-27 de septiembre de 2014. Asimismo, las brigadas de "búsqueda ciudadana" a nivel regional y nacional han visibilizado la problemática y han transformado a los deudos en activistas, que denuncian la inoperancia o complicidad de las autoridades, y en forenses-ciudadanos que, a veces actuando en el límite de lo permitido por la ley, cuestionan a las autoridades, a los técnicos y a los expertos en el propio campo de sus competencias y funciones. ${ }^{2}$

La Ley General en Materia de Desaparición Forzada de Personas, Desaparición Cometida por Particulares y del Sistema Nacional de Búsqueda del 2017 prevé la creación de un Registro Nacional de Fosas Comunes y Clandestinas, así como de los respectivos registros estatales, los cuales empiezan a construirse. Sin embargo, no contiene una definición de "fosa clandestina", la cual podría incluirse, por lo menos, en las legislaciones estatales, o bien, en los protocolos homologados de búsqueda y de investigación para casos de desaparición de personas que emiten la Comisión Nacional de Búsqueda y la Fiscalía General de la República, a través de la Conferencia Nacional de Procuración de Justicia.

En enero de 2020 todavía faltaban veintitrés entidades federativas por aprobar su legislación local según mandata la Ley General; veintiocho de ellas no habían armonizado la Ley de Declaración Especial de Ausencia para Personas Desaparecidas; siete aún no habían creado su fiscalía especializada en delitos de desaparición, y finalmente tres tenían pendiente la creación de su comisión local de búsqueda de personas. ${ }^{3}$ Para el mes

\footnotetext{
${ }^{2}$ Anne Huffschmid, "Huesos y humanidad. Antropología forense y su poder constituyente ante la desaparición forzada”, p. 198.

${ }^{3}$ ONU-Derechos Humanos, "ONU-DH: a dos años de su entrada en vigor, es necesario redoblar esfuerzos en la implementación de la ley de desaparición de personas".
} 
de agosto, todavía faltaba la Comisión de Búsqueda del estado de Aguascalientes.

Guanajuato salió de "la lista negra" apenas el 14 de mayo de 2020, tras la aprobación, por parte del Congreso estatal, de la Ley de Búsqueda de Personas Desaparecidas. Un impulso llegó del hecho de que, entre 2018 y 2019, se comenzó a formar un movimiento de colectivos y familiares de personas desaparecidas en la entidad, con cierta capacidad de presión, visibilización de las víctimas de desaparición e incidencia política, el cual exigió, ante las resistencias de las autoridades, una mayor participación social en el proceso legislativo. ${ }^{4}$

Por otro lado, la Fiscalía General del Estado de Guanajuato (FGE) nunca ha admitido de modo oficial la presencia de fosas clandestinas en su territorio, pese a investigaciones hemerográficas que reportan lo contrario. "Mientras en formas siempre más crueles la violencia se hace global, la lengua se muestra incapaz de renovarse para nombrarla y tiende, más bien, a enmascararla", ${ }^{6}$ pues la minimización o negación tanto de las desapariciones como de los demás espacios clandestinos de disposición u ocultamiento de los cuerpos ha sido una constante en la mayoría de los estados mexicanos, por lo que Guanajuato no ha sido la excepción.

El artículo 3 de la Ley de Búsqueda de Personas Desaparecidas en Guanajuato ${ }^{7}$ no contempla la de "fosa clandestina" entre las definiciones básicas, aunque su inclusión favorecería una adecuada integración justamente del Registro Estatal de Fosas Comunes y de Fosas Clandestinas, que concentra la información respecto de las fosas comunes, legales, que existen en los cementerios y

${ }^{4}$ Fabrizio Lorusso, "Desaparecer en Guanajuato", Animal Político. Disponible en: <https:/www.animalpolitico.com/seguridad-180/desaparecer-en-guanajuato/>. ${ }^{5}$ Óscar Uscanga, "Son desaparecidos otro problema en Guanajuato", Reforma, México, 1/3/2020.

${ }^{6}$ Adriana Cavarero, Horrorismo. Nombrando la violencia contemporánea, p. 17.

${ }^{7}$ Véase el texto íntegro en: <https://portal.fgeguanajuato.gob.mx/PortalWebEstatal/Archivo/normateca/411.pdf>. 
panteones de los municipios del Estado y también de las fosas clandestinas que la Fiscalía General y la Comisión Estatal de Búsqueda de Personas localicen. Esto permitiría mayor transparencia, rendición de cuentas, garantía de los derechos de las víctimas y una caracterización más efectiva de este fenómeno que incorpora graves y múltiples violaciones a derechos humanos.

Cabe destacar que la noción de "fosa clandestina" no es unívoca, sino que depende de las disciplinas que se acerquen a su conceptualización (antropología, derecho, sociología, criminología, arqueología, por ejemplo) y, asimismo, de las finalidades o funciones que se le quieran dar en un contexto determinado, por lo cual esto abre la posibilidad de pensar definiciones orientadas a la mayor protección de los derechos humanos de las personas desaparecidas, de las víctimas indirectas, de la sociedad y, desde luego, al interés de las instancias encargadas de la búsqueda, de la investigación, del esclarecimiento de la verdad y la impartición de justicia, en correspondencia con criterios fijados a nivel nacional.

Las cifras oficiales tienden a minimizar el número de fosas clandestinas. Hay una dificultad objetiva en saber cuántas son y en dónde se ubican, también porque hay divergencias en los criterios de clasificación entre distintas agencias federales, y entre éstas y las estatales. No han existido requisitos claros en México para que "los estados informen al gobierno de estas fosas clandestinas, y el gobierno federal no mantiene una base de datos exhaustiva sobre las mismas", ${ }^{8}$ aunque más recientemente se ha estado realizando un esfuerzo de catalogación y recuento a nivel nacional y se ha informado, en términos generales y con cifras agregadas, acerca de esta realidad: la CNB (Comisión Nacional de Búsqueda de Personas) y la Subsecretaría de Derechos Humanos, Población y Migración de la Segob (Secretaría de Gobernación) llevan el proceso de recolección y homologación de datos, y confirmaron,

\footnotetext{
${ }^{8}$ Open Society Justice Foundations, Atrocidades innegables: confrontando crimenes de lesa humanidad en México, p. 38.
} 
al 31 de diciembre de 2019, la cifra de 3631 fosas clandestinas, 61637 personas desaparecidas y más de 37000 cuerpos sin identificar, lo cual habla de una preocupante crisis forense nacional. ${ }^{9}$ Al corte siguiente, del 30 de junio de 2020, el número de fosas había aumentado a 3978 con 6625 cuerpos exhumados, mientras que eran 73201 las personas desaparecidas y no localizadas a la fecha del 13 de julio de 2020. ${ }^{10}$

Este trabajo discute el concepto de fosa clandestina a partir de una revisión de la literatura académica nacional e internacional sobre el tema, con el fin de entender la evolución histórica en su uso y significado a nivel internacional, pero particularmente en México y el estado de Guanajuato. El caso de la historia reciente de esta entidad, con la crisis de violencia, homicidios y de derechos humanos que ha experimentado, de la mano del aumento de las desapariciones y las fosas clandestinas, ha sido construido aquí mediante la sistematización y el análisis de fuentes hemerográficas y documentos, tanto oficiales como producidos por colectivos de búsqueda, así como a través de fuentes primarias derivadas de la observación participante en algunos de los procesos descritos. La situación de las fosas clandestinas en Guanajuato y la postura de la Fiscalía estatal al respecto representan un caso de estudio que narra una situación común a varias entidades. Se hace también un balance crítico del proceso legislativo y el debate político-social sobre la Ley de Búsqueda de Personas Desaparecidas del Estado de Guanajuato y las propuestas de definición de fosas clandestinas que fueron planteadas, sin éxito, por académicos, colectivos y organizaciones internacionales para su inclusión en la ley.

\footnotetext{
${ }^{9}$ Comisión Nacional de Búsqueda de Personas Desaparecidas, "Informe sobre fosas clandestinas y registro nacional de personas desaparecidas y no localizadas", p. 17.

${ }^{10}$ Comisión Nacional de Búsqueda, "Búsqueda, identificación y registro de personas desaparecidas (corte al 13 de julio de 2020)", pp. 2 y 6.
} 
La Real Academia de la Lengua española define fosa como "enterramiento, sepulcro", o bien, "hoyo en la tierra para enterrar uno o más cadáveres", mientras que lo "clandestino" se refiere a algo "secreto, oculto, y sobre todo hecho o dicho en secreto por temor a la ley o para eludirla". Y, por último, "inhumar" significa "enterrar" o "poner algo o alguien debajo de tierra". En el uso común en México, así como en el entendimiento de distintas autoridades y registros, la "fosa clandestina" se ha construido como un concepto cada vez más amplio, que incluye entierros, es decir, sitios con cadáveres o restos inhumados, más o menos profundos, que por sus características son fosas en sentido estricto. Sin embargo, también llega a describir entierros superficiales, y todos los sitios de hallazgo en donde haya cuerpos abandonados de forma ilegal. Entonces, se registran como "fosa clandestina" distintos tipos de lugares de hallazgo de cuerpos, identificados por el intento de ocultar cadáveres y evadir la ley, más que por cuestiones meramente técnicas o físicas. El término llega incluso a ser reivindicado y apropiado como forma de denuncia pública y elemento de su lucha por parte de grupos y brigadas de buscadores de personas que rastrean el terreno para encontrar "tesoros", o sea, huesitos y restos de sus seres queridos. ${ }^{11}$

La Secretaría de Gobernación definió fosa clandestina como un "lugar en el cual se inhumaron cuerpos o restos humanos, sin seña alguna que denote su existencia, sin el conocimiento de las autoridades o con el propósito de ocultar el paradero de una o más personas". ${ }^{12}$ Ésta es una primera base para integrar registros estatales y el Registro Nacional. Además, señala la Secretaría, no debe confundirse el término de "fosas clandestinas" con el de "fo-

${ }^{11}$ Pietro Ameglio, “'No buscamos huesos, buscamos tesoros': V brigada de Búsqueda de Personas Desaparecidas en Veracruz".

${ }^{12}$ Secretaría de Gobernación, "Reporte: Fosas clandestinas diciembre 2018 - 13 de mayo 2019", p. 3. 
sas comunes", ya que este último se refiere a "lugares en los cuales las autoridades inhuman cuerpos humanos de manera no individualizada, esto es, sin sepultura propia, sea que se conozca o no su identidad en vida". ${ }^{13}$

El énfasis en datos técnicos, dimensiones, número o disposición de los cuerpos sepultados para determinar qué son las fosas comunes, en especial en contextos de guerra y otros conflictos armados, caracterizó una primera fase de la arqueología forense, según la cual las características centrales de una fosa eran la presencia de dos o más cuerpos, enterrados juntos y en contacto físico entre estos, ${ }^{14}$ pero a partir de la última década del siglo pasado el enfoque se ha actualizado y ampliado, a la luz de las guerras en la exYugoslavia, entre otras, y de las luchas por la memoria sobre las graves violaciones a los derechos humanos en América Latina.

Mientras aumentaban las exhumaciones y excavaciones de fosas comunes con víctimas de abusos a los derechos humanos, para su conceptualización se empezaron a considerar "las formas de muerte de los individuos enterrados dentro de las fosas, así como los aspectos jurídicos de los enterramientos": ${ }^{15}$ en 1993 Bacre Waly Ndiaye, reportero especial de Naciones Unidas sobre ejecuciones extrajudiciales, sumarias o arbitrarias, formula esta definición, retomada posteriormente por el Tribunal Penal Internacional sobre Yugoslavia: "Emplazamientos en donde se hubiese sepultado a tres o más víctimas de ejecuciones extrajudiciales, sumarias o arbitrarias, que no hubiesen muerto en combate o en enfrentamientos armados". ${ }^{16}$ Aquí se refiere a entierros colectivos, de más personas, y queda claro el contexto generalizado de viola-

${ }^{13}$ Ibidem, p. 3.

${ }^{14}$ A. K. Mant, "Knowledge Acquired from Post-War Exhumations", pp. 65-78. ${ }^{15}$ Jugo y Sari Wastell, "Disassembling the Pieces, Reassembling the Social: The Forensic and Political Lives of Secondary Mass Graves in Bosnia and Herzegovina”, p. 145.

${ }^{16}$ Naciones Unidas, UN Doc E/CN.4/1993/50. Situación de los derechos humanos en el territorio de la antigua Yugoslavia, p. 67. 
ciones graves, como son las ejecuciones extrajudiciales que allí se cometieron.

Un enfoque más holístico y antropológico, menos "técnico", se resume en la propuesta de Schmitt sobre fosas como espacios que contienen restos de más de una víctima que tienen en común causas y formas de la muerte, la cual también distingue entre fosas comunes con relevancia e interés forense, de tipo "penal/criminal", y fosas que no ameritan investigación forense, por ejemplo las fosas comunes legales o creadas por el Estado. ${ }^{17}$ Las fosas penales resultan del enterramiento de cuerpos de víctimas de graves violaciones a derechos humanos, contrarias al derecho internacional humanitario, mientras que las fosas comunes no-penales se dirigen a la disposición temporal de restos humanos tras catástrofes naturales, por ejemplo, para que sean enterrados en definitiva en otro sitio o momento. ${ }^{18}$

Según estas categorías, las fosas -tanto las colectivas o comunes como las individuales, que respondan al tipo "criminal-penal"serían equivalentes, dada la ilegalidad y clandestinidad de su naturaleza, a las "fosas clandestinas" en el contexto mexicano, en donde, sin embargo, no ha habido una admisión formal de la existencia de un conflicto armado interno, aun cuando algunos estudios sí lo sostienen contundentemente, ${ }^{19} \mathrm{y}$ se debate si las violaciones a derechos humanos de la llamada "guerra a las drogas" se pueden tratar como crímenes de lesa humanidad y violaciones al derecho internacional humanitario. ${ }^{20}$

\footnotetext{
${ }^{17}$ Stefan Schmitt, "Mass Graves and the Collection of Forensic Evidence: Genocide, War Crimes and Crimes against Humanity".

${ }^{18}$ C. Perera y C. Briggs, "Guidelines for the Effective Conduct of Mass Burials Following Mass Disasters: post-Asian Tsunami Disaster Experience in Retrospect".

${ }^{19}$ Universiteit Leiden, The Situation of Drug-Related Violence in Mexico from 2006-2017: A Non-International Armed Conflict?

${ }^{20}$ CMDPdh (Comisión Mexicana para la Defensa y Promoción de los Derechos Humanos), Crimenes de lesa humanidad en México en el marco de la lucha contra las drogas.
} 
La fosa clandestina, en este sentido, se interpreta como parte de "paisajes forenses", o sea "paisajes testigos de la deshumanización, que a la vez devienen escenarios donde se busca revertir sus efectos", ${ }^{21}$ en donde se cometieron graves violaciones a los derechos humanos, con independencia de su "estatus" internacional o de la declaración formal de un conflicto armado, y en donde los perpetradores intentan ocultar el paradero de la víctima o destruir evidencias mediante enterramientos profundos o disposiciones superficiales.

Las fosas comunes o individuales, de tipo penal, son hechas con el fin de esconder los crímenes cometidos, negar el derecho a la verdad y la justicia, y establecen una división de la población entre víctimas y perpetradores, pues "los aspectos sociales que rodean las fosas comunes penales se combinan para formar un conjunto de circunstancias que hacen que sus creadores y los parientes se bifurquen en dos grupos muy distintos, en lados opuestos de interés respecto de estas fosas". ${ }^{22}$ En el caso de las fosas clandestinas en México estamos hablando de esta tipología de sitios, en que se requiere una diligencia forense por graves violaciones a derechos humanos y crímenes relevantes penalmente que allí se cometieron, así que las fosas y los restos depositados "deben entenderse como distintos tipos de actantes en la red que conceptualiza la memoria y la justicia". ${ }^{23}$

En un informe de 2017 que mapeó las fosas clandestinas de México, éstas se definen, para fines de mapeo hemerográfico y como aclaración metodológica, como "sitio donde uno o más cuerpos y/o restos de personas fueron enterrados o semienterrados, de forma anónima e/o ilegal, con el intento de ocultar o destruir evidencia, y que después fueron exhumados por particu-

${ }^{21}$ Anne Huffschmid, "Paisajes forenses: sobre cómo mirar, leer y narrar las fosas intervenidas de nuestro tiempo", p. 41.

${ }^{22}$ Admir y Wastell, "Disassembling the Pieces”, op. cit., p. 147.

${ }^{23}$ Ibidem, p. 147. 
lares u autoridades". ${ }^{24}$ También se especifica que "dicho lugar de exhumación representa una disputa social y política por recuperar la identidad de la/s persona/s inhumadas, acceder a la justicia, restablecer derechos individuales y colectivos, así como preservar la verdad y la memoria, derivado de un contexto de violaciones a derechos humanos". ${ }^{25}$ Este aspecto es muy importante para construir propuestas de definición, incluso con fines de incidencia legislativa a nivel estatal, para ir más allá de consideraciones sólo técnicas y para destacar el contexto de graves violaciones a derechos humanos que caracteriza el "espacio doliente" ${ }^{26} \mathrm{y}$ de excepción que representa hoy la fosa clandestina en México.

Relacionada con estas consideraciones se encuentra la descripción de la fosa clandestina en el ámbito de posibles "escenarios de búsqueda”, o sea, según la Comisión Nacional de Búsqueda, como lugares en que "la experiencia indica que es posible hallar a personas que probablemente sean buscadas, o sus restos mortales, y sobre el cual la Búsqueda Generalizada produce y recopila información en forma sistemática", ${ }^{27}$ siendo éstos, por ejemplo, "los albergues, hospitales psiquiátricos, fosas comunes, contextos de hallazgo de restos humanos (como fosas clandestinas, lugares de cremación clandestina o cuerpos de agua), estaciones migratorias, centros de reinserción social y de atención de adicciones, centros de salud y el espacio público en el que puede encontrarse a personas en situación de calle". ${ }^{28}$ En este sentido, la misma definición de un "escenario" en que se realizan búsquedas, que pueden ser

${ }^{24}$ Denise González Núñez, Jorge Ruiz Reyes, Lucía Guadalupe Chávez Vargas y José Antonio Guevara Bermúdez, Violencia y terror. Hallazgos sobre fosas clandestinas en México, p. 24.

${ }^{25}$ Ibidem, p. 24.

${ }^{26}$ Arturo Aguirre, Nuestro espacio doliente. Reiteraciones para pensar en el México contemporáneo.

${ }^{27}$ Comisión Nacional de Búsqueda, "Proyecto de protocolo homologado para la búsqueda de personas desaparecidas y no localizadas (versión 5/5/2020 para fortalecimiento)", p. 27.

${ }^{28}$ Idem.

Una discusión sobre el concepto de fosa clandestina y el contexto... / I 39 
institucionales, pero también, y cada vez más en el caso mexicano, de tipo ciudadano, en brigadas y colectivos, se nutre de una semántica y una praxis que va más allá de "una escena del crimen" y la extiende en sus sentidos y representaciones para la comprensión de fenómenos extremos y complejos social e históricamente.

Por otro lado, el Protocolo homologado de investigación para los delitos de Desaparición Forzada y desaparición cometida por particulares de la Conferencia Nacional de Procuración de Justicia, ${ }^{29}$ en el cual tampoco se encuentra una definición de fosa clandestina, habla, citando a Hochrein, de "escenas del crimen que involucran inhumaciones", en las que la fosa se interpreta como un elemento y "es una parte de la escena del crimen que no puede ser recolectada, pero si se excava apropiadamente, se puede obtener información valiosa al respecto de las herramientas con las que fue excavada, sus características geofísicas, así como otros cambios en el subsuelo que puedan ser preservados". ${ }^{30}$

Desde un enfoque de corte más criminológico y positivista, el Protocolo sugiere realizar análisis "sobre los sitios de localización de cadáveres y restos humanos, atendiendo las condiciones de cada caso y forma de ocultamiento (ya sea inhumación, incineración, desintegración, destrucción o abandono)" y, gracias a formas de estudio multidisciplinario de estos sitios "desde distintas disciplinas de las ciencias exactas", conseguir "una mejor comprensión de las circunstancias que rodean y en las que se llevó a cabo el hecho delictivo" ${ }^{31}$ En efecto, la expresión que se maneja, dentro del estudio del análisis de contexto, es la de "condiciones de contexto forense", referida a "poner el objeto de estudio en el momento y tiempo exacto con relación a otros objetos de

${ }^{29}$ Conferencia Nacional de Procuración de Justicia (CNPJ), Protocolo homologado de investigación para los delitos de desaparición forzada y desaparición cometida por particulares, pp. 83-85.

${ }^{30}$ Michael J. Hochrein, "Buried Crime Scene Evidence: The Application of Forensic Geotaphonomy in Forensic Archaeology”, pp. 83-99.

${ }^{31}$ CNPJ, Protocolo homologado, op. cit., pp. 84-85. 
estudio", por lo que "para el análisis y estudio de un hallazgo de cuerpos o restos humanos, es necesario que, desde el punto de vista de las disciplinas de la antropología y arqueología forense, se determinen las circunstancias en las que se efectuó la localización". ${ }^{32}$ Cabe destacar que, si bien ahonda en su tratamiento, diligencias y registro, tampoco el Protocolo para el tratamiento y la identificación forense de la que fue la Procuraduría General de la República, hoy Fiscalía, cuenta con una definición precisa y explícita de fosa clandestina. ${ }^{33}$

La CNDH (Comisión Nacional de Derechos Humanos) definió una fosa clandestina como "aquella que se realiza de manera secreta u oculta por ir en contra de la ley y su propósito es esconder lo que en ella se deposita, evitando entre otras cosas que las autoridades puedan sancionar e investigar las razones de la inhumación; las personas que realizan este tipo de fosas saben que su acción es ilegal”. ${ }^{34}$ La Comisión no se ha enfocado en enumerar características técnicas de dimensión o profundidad de una "fosa", sino más bien en el hecho de que se debe considerar un sitio clandestino de inhumación con el propósito de "esconder" lo que allí se dispone. De hecho, esta definición fue emitida como parte de una recomendación relativa al caso de las fosas de Tetelcingo, Morelos, que contenían más de ciento cincuenta cuerpos, y como fosas comunes se pueden entender ante todo las que normalmente son dispuestas por la autoridad para inhumar más de un cuerpo, y clandestinas a la vez, ya que "la fosa fue creada por la misma Fiscalía del Estado que inhumó de manera ilegal, sin

\footnotetext{
${ }^{32}$ Ibidem, p. 84.

${ }^{33}$ Procuraduría General de la República, Protocolo para el tratamiento y la identificación forense.

34 Comisión Nacional de los Derechos Humanos, "Recomendación No. $48 / 2016$, Sobre el caso de la violación al derecho de acceso a la justicia en la modalidad de inadecuada procuración de justicia y violación al derecho a la verdad, relacionado con la irregular inhumación de 119 cadáveres en la comunidad de Tetelcingo, Municipio de Cuautla”, p. 57.
} 
ningún tipo de protocolo ni documentación, estos cuerpos" ${ }^{35}$ Funcionarios del Estado crearon, pues, un sitio clandestino de inhumación masiva.

En este contexto, una conceptualización extendida de las fosas clandestinas las considera "como cualquier sitio que tiene como propósito ocultar o destruir evidencia", ${ }^{36}$ siendo rasgos fundamentales de éste: su derivación de uno o más actos ilícitos y la presencia de un entierro anónimo, lo cual las diferencia de "entierros 'informales' sin seńalizar o féretros que se concibieron para inhumar, más que para esconder a los fallecidos". ${ }^{37}$

Siguiendo a Komar, "por evidencia se entienden cuerpos o restos de personas enterradas o semienterradas", ${ }^{38}$ por lo que cualquier sitio en que haya evidencia de cuerpos, cadáveres o restos de personas enterradas o semienterradas, más o menos en la superficie, debería considerarse como fosa clandestina. La noción de "cualquier sitio", señala Ruiz con base en informes de Naciones Unidas, es aquí ampliada, ya que contempla incluso lugares parecidos a, o con función de, fosas, como pozos o ríos secos. ${ }^{39}$ Una caracterización de las fosas clandestinas para procesos penales internacionales, pero útil también para el contexto mexicano actual, "tiene que reunir tanto los elementos técnicos provenientes de las disciplinas forenses como de aquellos elaborados desde la visión jurídica y de derechos humanos a lo largo de los años". ${ }^{40}$

Aunque en el derecho internacional no haya una definición de lo que sería una fosa común ilegal o entierro masivo, se entiende

${ }^{35}$ Carolina Robledo, "Peinar la historia a contrapelo: reflexiones en torno a la búsqueda y exhumación de fosas comunes en México”, p. 21.

${ }^{36}$ Jorge Ruiz Reyes, "Fosas clandestinas y su relación con crímenes de lesa humanidad. Propuesta metodológica para la documentación de casos que determinen responsabilidad penal internacional en México", p. 115.

${ }^{37}$ Debra Komar, "Patterns of Mortuary Practice Associated with Genocide Implications for Archaeological Research", p. 126.

${ }^{38}$ Debra Komar apud Ruiz Reyes, "Fosas clandestinas", op. cit., p. 115.

${ }^{39}$ Ruiz Reyes, "Fosas clandestinas”, op. cit., p. 115.

${ }^{40}$ Ibidem, p. 115. 
por lo general como un sitio que contiene una multitud de restos humanos enterrados, mientras que en la legislación iraquí es un "terreno o lugar que contiene los restos de más de una víctima, que fueron enterrados o escondidos". ${ }^{41}$

Jessee y Skinner, en su taxonomía de fosas, definen que "una fosa clandestina es cualquier lugar que contenga dos o más cuerpos, colocados indiscriminadamente o deliberadamente, de víctimas que han muerto como resultado de ejecuciones extrajudiciales, sumarias o arbitrarias, sin incluir a las personas que han muerto como resultado de enfrentamientos armados o grandes catástrofes conocidas". ${ }^{42}$ Aunque las últimas dos referencias mencionadas hablan de fosas o entierros masivos, lo que importa en este caso es su definición como sitios de disposición ilegal-irregular de cuerpos sin identificar, sin considerar la cantidad de los cuerpos, como víctimas de violaciones graves a derechos humanos, entre las cuales desde luego ha de incluirse la desaparición forzada de personas.

Desde la investigación antropológica y social, Komar concibe el entierro clandestino en función de que hubo un intento de ocultar o destruir evidencia, derivado del acto ilícito, ${ }^{43}$ y Rosenblatt caracteriza antropológica y socialmente las fosas como espacio con combinación de cadáveres de personas, personas en duelo y expertos forenses, más allá de las otras características técnicas ya mencionadas. ${ }^{44}$ Hablar de cementerio o fosas ilegales implica que éstas son "invisibles, carecen de derechos de propiedad, niegan significados espirituales, religiosos y políticos sobre la muerte y resurrección, destruyen identidades individuales y co-

\footnotetext{
${ }^{41}$ UNAMI/OHCHR (Un Assistance Mission for Iraq, Office of the High Commissioner for Human Rights), (2018), Unearthing Atrocities: Mass Graves in territory formerly controlled by ISIL, p. 2.

${ }^{42}$ Erin Jessee y Mark Skinner, "A Typology of Mass Grave and Mass Grave-Related Sites", p. 56.

${ }^{43}$ Komar, "Patterns", op. cit., p. 126.

${ }^{44}$ Adam Rosenblatt, Digging for the Disappeared. Forensic Science after Atrocity, p. 14 .
}

Una discusión sobre el concepto de fosa clandestina y el contexto... / I43 
lectivas dentro de la mezcolanza de restos humanos, e impiden o suspenden el rito del entierro y el recuerdo duradero". ${ }^{45}$

En la violencia dolosa, manifestada en el espacio público por las fosas, y su conceptualización, se entremezclan elementos de pragmática política, de ejercicio (o no) del derecho, de formas de la regulación y el control social, entre miedo y ejercicio de libertad, y de modos de pensar la comunidad ante las desapariciones forzadas y las fosas comunes de los años de la (mal) llamada narcoguerra en México, ${ }^{46}$ la cual, más que una lucha contra el crimen organizado y la droga, representa una militarización de la seguridad pública y una expresión de la gobernanza neoliberal y del capitalismo antidroga con funciones de control social. ${ }^{47}$

El espacio doliente de la fosa implica una memoria común de los daños ocasionados por poderes políticos y fácticos, ligados al llamado narco-poder, al necro-poder y a la gestión necropolítica sobre vidas vulnerables o dispensables; ${ }^{48}$ una secuencia de datos e informes sobre la sistematicidad y continuidad de múltiples violencias que aniquilan la integridad corporal de las víctimas directas; la violación nítida y directa de derechos humanos implicada en la creación de las fosas, y la consiguiente destrucción del espacio público y de la propia condición humana de las víctimas. ${ }^{49}$

\footnotetext{
${ }^{45}$ Antonius C. G. M. Robben, "Exhumations, Territoriality, and Necropolitics in Chile and Argentina”, p. 58.

${ }^{46}$ Aguirre, Nuestro espacio doliente, op. cit., p. 85.

${ }^{47}$ Dawn Marie Paley, Capitalismo antidrogas. Una guerra contra el pueblo.

${ }^{48}$ Rossana Reguillo, "De las violencias: caligrafía y gramática del horror"; Sayak Valencia, Capitalismo gore. Control económico, violencia y narcopoder; Ariadna Estévez, "El dispositivo necropolítico de producción y administración de la migración forzada en la frontera Estados Unidos-México".

${ }^{49}$ Aguirre, Nuestro espacio doliente, op. cit., pp. 85-86.
} 


\section{2) Las fosas Clandestinas en Guanajuato}

Según estudios con fuentes hemerográficas, en Guanajuato, entre 2009 y el 31 de julio de 2020, fueron hallados 109 sitios clasificables como fosas clandestinas con un total de 268 cuerpos en 29 municipios, concentrando Pénjamo (con 11 fosas), Irapuato (11), Celaya (8), Villagrán (7) y Acámbaro (7) cerca del 40\% del total de fosas registradas, mientras que los municipios de Villagrán (con 43 cuerpos), Irapuato (40), Celaya (23), Apaseo el Alto (18) y Pénjamo (17) reúnen el 53\% del total cuerpos exhumados. ${ }^{50}$ No obstante, la Fiscalía General del Estado no había reconocido ninguna oficialmente, por lo menos hasta agosto de $2020 .^{51}$

También en los informes sobre el histórico de fosas de la Segob y la CNB, ${ }^{52}$ Guanajuato aparece como uno de los cinco estados de la República que declara no tener ninguna fosa clandestina, pese a evidencias, videos, notas y fotos difundidas por la prensa, así como a la información de los colectivos de víctimas, sobre decenas de hallazgos de cuerpos y entierros clandestinos, los cuales,

${ }^{50}$ Jorge Ruiz Reyes, Fabrizio Lorusso y Óscar Elton Susarrey, Informe sobre la situación de las fosas clandestinas en Guanajuato (2009 a julio de 2020). Cabe destacar que este informe, publicado junto con la base de datos cvs/Excel sobre las fosas clandestinas en Guanajuato, utiliza notas de prensa nacionales e internacionales, encontradas por los autores a través de buscadores (Google) en internet y de bases de datos provistas por las organizaciones Article19 (Oficina para México y Centroamérica), Data Cívica y CMDpdh (Comisión Mexicana para la Defensa y la Promoción de los Derechos Humanos). No hay ninguna información adicional de parte de la FGE de Guanajuato sobre fosas clandestinas. El informe sigue la definición de fosa y la metodología de González Núñez, Ruiz Reyes, Chávez Vargas y Guevara Bermúdez, Violencia y terror, op. cit.

${ }^{51}$ En la respuesta a la solicitud la Unidad de Transparencia, después de varias solicitudes por parte de ciudadanos y de señalamientos de la Comisión Nacional de Búsqueda sobre la opacidad de su información pública, dio a conocer el dato al corte del 13 de julio de 2020 de " 2178 personas no localizadas (paradero desconocido)", un eufemismo que, en realidad, representa el total de personas desaparecidas en la entidad. Unidad de Transparencia de la Fiscalía General del Estado, "Oficio 421/2020 Respuesta a solicitud de acceso a información pública con folio de referencia 00924720”, 13/08/2020.

${ }^{52}$ Comisión Nacional de Búsqueda, "Informe sobre fosas clandestinas", op. cit.

Una discusión sobre el concepto de fosa clandestina y el contexto... / I45 
a nivel federal o en otras entidades, se clasificarían, al menos en parte, como "fosas". En Guanajuato no son reportadas de esta forma, lo que contribuye a ocultar el fenómeno.

La Procuraduría General de Justicia del Estado de Guanajuato informó, por conducto del Asesor Adscrito al Despacho del C. Procurador, Enlace Institucional para el Seguimiento de Casos de Personas no Localizadas, que, de acuerdo con la información proporcionada por el director general de la Agencia de Investigación Criminal, no se obtuvieron datos relacionados con fosas clandestinas. Sin embargo, el muestreo hemerográfico realizado por esta Comisión arrojó que se localizaron en esa entidad 18 entierros ilegales de donde fueron exhumados 22 cadáveres, de conformidad con lo siguiente. ${ }^{53}$

La prensa local ha difundido recientemente notas con conteos de las fosas clandestinas y los cadáveres y restos encontrados. En enero de 2020 el portal Zona Franca ${ }^{54}$ mencionaba el hallazgo de 23 fosas y 127 cuerpos en cinco años, y una nota de redacción del suplemento $A M$ Express $^{55}$ del diario $A M$ contó 15 fosas acumuladas desde 2018, mientras que el colectivo de familias de personas desaparecidas A tu Encuentro declaró en mayo tener información sobre 19 fosas clandestinas encontradas en $2020 .^{56}$

Sin embargo, el 13 de febrero de 2020, ante las solicitudes 00345020 y $00349020,{ }^{57}$ que pedían información sobre fosas

${ }^{53}$ Comisión Nacional de los Derechos Humanos, "Informe Especial sobre Desaparición de Personas y Fosas Clandestinas en México”, p. 481.

54 "Crece en Guanajuato el número de cuerpos encontrados en predios abandonados”, Zona Franca, 4/1/2020. Disponible en: <https://zonafranca.mx/seguridad/ok-propuesta-diciembre-guanajuato-cementerio-clandestino/>.

55 "Las fosas...", AM Express, 06/01/2020.

${ }^{56}$ Bryam Torres, "Descubren familias 19 fosas con restos humanos en Guanajuato", Diario AM, 28/05/2020. Disponible en: <https:/www.am.com.mx/ guanajuato/noticias/Descubren-familias-19-fosas-con-restos-humanos-en-Guanajuato-20200528-0028.html>.

${ }^{57}$ Unidad de Transparencia de la Fiscalía General del Estado, “Oficio 141/2020 
clandestinas, cuerpos hallados y desglose de sus características entre 2016 y 2019, la Unidad de Transparencia de la Fiscalía respondió que no se contaba con registros de fosas en el estado bajo contexto referido en el periodo peticionado, es decir, lo hizo con una negativa a reconocer la presencia de este tipo de inhumación, lo cual ha reiterado en varias otras respuestas a peticiones semejantes de distintos ciudadanos. Este tipo de respuesta se ha repetido de la misma manera en los ańos anteriores.

El 18 de agosto de 2018 el entonces procurador de Justicia del Estado, Carlos Zamarripa, hoy fiscal general, mencionó la presencia de cinco fosas clandestinas, definidas como excavaciones "para ocultar", y no ha sido la única vez en que el funcionario, ante la prensa, ha hablado de fosas clandestinas, pero oficialmente éstas y sus características o ubicación no han sido confirmadas, pues los registros no existen o no se dan a conocer, por lo que lo anterior llega a ser un factor de ocultamiento de la verdad. ${ }^{58}$

Este ejemplo indica discrepancias importantes entre, por un lado, los datos sobre fosas de los medios de comunicación y los que recolectan académicos y colectivos de familiares, $y$, por otro, la información pública que dan las autoridades con base en sus registros. Lo anterior evidencia la ausencia de registros forenses adecuados, conforme a la Ley General y la estatal en materia de desaparición, así como deficiencias en el Registro estatal de personas desaparecidas y no localizadas, así que la Comisión Nacional de Búsqueda clasificó con "semáforo rojo" a Guanajuato por la falta de una adecuada y actualizada rendición de cuentas al respecto. ${ }^{59}$

\footnotetext{
Respuesta a solicitud de acceso a información pública con folio de referencia 00345020 y 389020, 13/02/2020". Disponible en: <https://lamericalatina.net/ wp-content/uploads/2020/06/Folios-00389020-y-00345020-respuesta-FGE13feb2020.pdf>.

${ }^{58}$ Vania Jaramillo, "Se coordinan cifras de desaparecidos, aclara Zamarripa", Periódico AM Express, 18/08/2018. Disponible en: <https://pressreader.com/ article/281659665950865>.

${ }^{59}$ Comisión Nacional de Búsqueda, "Informe sobre fosas clandestinas", op. cit., p. 31 .
}

Una discusión sobre el concepto de fosa clandestina y el contexto... / I47 
La FGE comunica en ocasiones, dentro de las respuestas a solicitudes de información, la forma como conceptualiza las fosas clandestinas. En respuesta a una solicitud pública con preguntas sobre el número de fosas clandestinas o de cualquier otro tipo de entierro, superficial o no, en la entidad, la Unidad de Transparencia de la FGE contestó:

Toda vez que de los términos de la petición se aprecia que el interés del peticionario es, propiamente, conocer información sobre registros de "fosas clandestinas" y diversos rubros relacionados con dicho tema, debe considerarse que la metodología y la terminología de la arqueología y antropología forense, en lo que a excavación y recuperación de restos humanos se refiere, proviene directamente de la arqueología tradicional. En ese tenor, el término fosa No se refiere a un entierro, sino a uno de sus diversos rasgos clasificatorios. ${ }^{60}$

Se hace referencia al hecho de que una fosa para la arqueología tiene ciertas definiciones y características técnicas, es excavada con cierta profundidad y amplitud. Sin embargo, tanto la literatura especializada como la praxis institucional en México amplían este concepto, incluso aterrizándolo al contexto de conflicto armado de facto y de graves violaciones a derechos humanos en muchos territorios, entendiendo por "fosa clandestina" cualquier lugar en que fueron abandonados y escondidos restos humanos enterrados o semienterrados, en profundidad o hasta en superficie, incluso barrancos, pozos, fosas naturales, presas y ríos, incorporando los ríos secos, por ejemplo. De esta forma, la FGE ahonda:

${ }^{60}$ Unidad de Transparencia de la Fiscalía General del Estado, “Oficio 53/2020 Respuesta a solicitud de acceso a información pública con folio de referencia 00052820", 20/01/2020. Disponible en: <https://fabriziolorusso.files.wordpress.com/2020/01/desaparecidos-gto-respuesta-folio-00052820-con-anexo-f. lorusso.pdf $>$. 
Bajo tales premisas, tomando en consideración los parámetros e integralidad de tales cuestionamientos, le manifiesto que no se cuenta con registros de fosas en el Estado bajo el contexto requerido durante el periodo peticionado. Ahora bien, respecto de entierros clandestinos, se manifiesta que con motivo del ejercicio de atribuciones de esta representación social, particularmente en el marco de lo dispuesto por el Protocolo para el Tratamiento e Identificación Forense, publicado en el Diario Oficial de la Federación el 3 de marzo de 2015, conforme a nuestra capacidad fáctica y jurídica, se informa que a partir de la fecha mencionada y al 31 de diciembre de 2019 se tiene registro de la localización de 50 cadáveres enterrados, puntualizando que no se cuenta con un documento o registro factible de consulta en el que se especifiquen de manera particular los lugares de los cadáveres y/o restos localizados. ${ }^{61}$

Cabe destacar que el número referido de 50 cadáveres enterrados era de tan sólo 20, al día 30 de septiembre de 2019, según información oficial, ${ }^{62}$ así que el número de cuerpos enterrados aumentó del 150\% en apenas tres meses, pero ninguno fue registrado dentro de fosas clandestinas, y además los datos específicos de cada hallazgo no están concentrados en un registro sino dispersos en las distintas carpetas de investigación de cada caso. En efecto, se declara que se tiene reporte de cadáveres enterrados y restos humanos, pero no se comunica, o se desconoce, en qué localidad estaban y en qué tipo de sitio o entierro estaban, lo cual es en especial preocupante con vistas a integrar un registro estatal y nacional y, sobre todo, por la tragedia humanitaria que representa de por sí. En una nota a pie de página de la misma respuesta se detalla sobre una posible definición de fosa/entierro:

\section{${ }^{61}$ Ibidem, p. 3.}

${ }^{62}$ Unidad de Transparencia de la Fiscalía General del Estado, "Oficio 558/2019 Respuesta a solicitud de acceso a información pública con folio de referencia 02686819", 21/10/2019, en <https://fabriziolorusso.files.wordpress.com/2019/10/ respuesta-folio-02686819.pdf>, p. 2. 
Resulta importante señalar que lo primero que debe tomarse en cuenta para una correcta clasificación, y posterior interpretación, de sitios de inhumación, son las cuestiones técnicas, a fin de determinar si se actualiza un determinado supuesto. En el caso de cadáveres enterrados, por ejemplo, si el entierro ocurre en la superficie o en el subsuelo. En ese sentido, si bien la expresión "entierro en superficie" puede parecer una flagrante contradicción u oxímoron, es de uso común en Arqueología, toda vez que el abordaje de ambos tipos de contexto es prácticamente el mismo, y la diferencia consiste en que en el "entierro en superficie" los restos son depositados en la superficie en vez de inhumados, y por ende no requieren ser excavados. Adicionalmente y para mayor referencia, habrá que considerar las condiciones y circunstancias particulares, tomando en cuenta las diversas clasificaciones o elementos característicos de "entierro" (primario y secundario, directo e indirecto, individual y múltiple, aislado o adyacente y sincrónico y diacrónico), siendo a la par de manifestar en tal sentido que se puede enterrar algo o alguien en una fosa, pero no toda fosa constituye un entierro, ni todo entierro se traduce o representa una fosa. ${ }^{63}$

La retorcida respuesta de la FGE admite la posibilidad de usar la expresión "entierros en superficie" cuando los restos no requieren ser propiamente excavados para su recuperación, así que serían restos enterrados, pero no por fuerza en la modalidad de fosa. En estos casos, en otros estados, se ha consolidado para fines de registro oficial, entre los colectivos y en la prensa, el uso del término "fosa", sobre todo si nos ubicamos en el contexto de la búsqueda de personas desaparecidas en terreno, en predios y cerros, y si el sitio tiene que ver con un intento de ocultamiento y con cuerpos incluso semienterrados. Es decir, se delata allí la presencia de un eslabón del mecanismo de la desaparición de personas.

${ }^{63}$ Unidad de Transparencia de la Fiscalía General del Estado, “Oficio 53/2020”, cit., p. 3. 
La expresión "entierro en superficie", o el concepto subyacente, además, es admitida por ejemplo en parte de la literatura académica, en notas técnicas y disertaciones sobre esta materia, mismas que hablan de sepulturas clandestinas en áreas boscosas, poco profundas, superficiales, excavadas incluso a mano, en lugares aislados o escondidos. ${ }^{64}$ En este sentido, por todo lo anterior, es sorpresivo que oficialmente no haya registro de fosas clandestinas en la entidad, ni se hable del tema, llegando de esta forma a invisibilizar tanto el fenómeno en sí -como parte del circuito en que se dan las desapariciones-, como la importancia de la verdad y la justicia, y a solapar de cierta manera las sistemáticas y acumuladas violaciones a los derechos humanos perpetradas en cada vez más espacios de excepción e impunidad en Guanajuato.

\section{3) De la negación a La Ley de Búsqueda}

\section{Y LAS PROPUESTAS DE DEFINICIÓN}

La crisis de inseguridad de Guanajuato no tiene precedentes en la historia reciente, pues fue el estado más violento del país en 2019 en términos de homicidios dolosos. En cinco meses, entre enero y mayo de ese año, fueron registrados 1493 homicidios dolosos, mientras que en el mismo periodo de 2020 la cifra, ya de por sí muy alta, se incrementó a 1907 víctimas de homicidios intencionales, que equivale al $27.7 \%$ más de lo que ya era un récord histórico. ${ }^{65}$

${ }^{64}$ J. K. Pringle, J. Jervis, J. P. Cassella y N. J. Cassidy, “Time-Laps Geophisycal Investigations over a Simulated Urban Clandestine Grave”; Morgan W. Hays, "Florida's Clandestine Graves: An Anthropological Perspective of the Dead"; y Michael Benjamin Alexander, "The Forensic Application of Soil: Clandestine Graves and human Remains Detection Dogs".

${ }^{65}$ Saúl Arrellano, "Guanajuato es la grandeza mortal de México", México Social, 02/06/2020. Disponible en: <http://mexicosocial.org/guanajuato-es-la-grandeza-mortal-de-mexico/>. 
Esta situación de descomposición del tejido social e inseguridad ya es innegable, ha provocado manifestaciones masivas e inéditas por parte de estudiantes, organizaciones, víctimas y otros sectores sociales, ${ }^{66} \mathrm{y}$ va de la mano del aumento de otros crímenes y violaciones de alto impacto, como las desapariciones, aunque en este caso el fenómeno ha sido negado o desdeñado por parte de las autoridades en diferentes ocasiones.

El exgobernador Miguel Márquez Márquez (2012-2018) declaró que los desaparecidos no son por la inseguridad sino por motivos de otra índole y muchos de ellos "se van con el novio o la novia". ${ }^{67}$ En octubre de 2019, según cálculos basados en información proporcionada por la Fiscalía General del Estado, había como mínimo unas 1443 personas desaparecidas en la entidad. ${ }^{68}$

En una comparecencia ante el Congreso local, el 11 de noviembre de 2019, en cambio, la titular de la Fiscalía Especializada en Delitos de Desaparición Forzada, Yolanda Ramírez Domínguez, afirmó que en Guanajuato sólo había once denuncias por los tipos penales de desaparición forzada o cometida por particulares, mientras que, en las calles del mundo real, ese mismo mes ya había decenas de familias de personas desaparecidas organizadas en un colectivo en Irapuato, las cuales lograron detener el proceso de aprobación de la Ley de Desaparición estatal porque no habían sido escuchadas y pedían más participación con la consigna "Sin las familias no". ${ }^{69}$

${ }^{66}$ Arnoldo Cuéllar, "Videocolumna 1102 20/Una Nueva energía social en Guanajuato", YouTube, 2020. Disponible en: <https://www.youtube.com/watch?$\mathrm{v}=\mathrm{wLisoI} 3$ hink $>$.

${ }^{67}$ Alfonsina Ávila, "Desapariciones en Guanajuato: la otra cara del terror", Newsweek México, 21/05/2019. Disponible en: <https://newsweekespanol. $\mathrm{com} / 2019 / 05 /$ desapariciones-en-guanajuato-la-otra-cara-del-terror1/>.

${ }^{68}$ Fabrizio Lorusso, "Son ya demasiadas las personas que nos faltan en Guanajuato”, PopLab, 28/10/2019. Disponible en: <https://poplab.mx/article/SonyademasiadaslaspersonasquenosfaltanenGuanajuatolacrisisdelosdesaparecidos $>$. 69 "Obligan al Congreso de Guanajuato a incluir a familiares en la revisión de leyes sobre desaparecidos", Proceso, 11/11/2019. Disponible en: <https://www. proceso.com.mx/606480/obligan-al-congreso-de-guanajuato-a-incluir-a-familiares-en-la-revision-de-leyes-sobre-desaparecidos $>$. 
El 9 de enero de 2020, después de una reunión entre colectivos de familiares de personas desaparecidas con defensores de derechos humanos y autoridades locales y federales, el secretario de Gobierno guanajuatense, Luis Ernesto Ayala, a la pregunta de los periodistas sobre las cifras de fosas clandestinas y personas desaparecidas, optó por no responder y señalar la exclusiva competencia de la Fiscalía al respecto. ${ }^{70}$

La titular de la Fiscalía Regional B de Irapuato, Claudia Mota, en diciembre de 2019, durante una reunión con familiares de víctimas, negó la existencia de fosas clandestinas en Guanajuato, ${ }^{71}$ como lo había hecho tres meses antes Sophia Huett, comisionada de la Unidad de Análisis y Estrategia para la Seguridad Ciudadana del estado, según la cual, debido a la velocidad y la fuerza de las instituciones de seguridad y de justicia del estado, no había fosas clandestinas y las autoridades eran capaces de actuar antes de que los cuerpos fueran ocultados. ${ }^{72}$

La Ley General en Materia de Desaparición de Personas, publicada el 17 de noviembre de 2017, mandata constituir, entre algo más, un Registro Nacional de Fosas Comunes y Clandestinas, por lo que las correspondientes leyes estatales han de crear los registros locales equivalentes; éstos están enlazados y se alimentan con los datos de las fiscalías locales sobre fosas comunes (legales) y clandestinas (ilegales). Todavía en agosto de 2020 este registro nacional no había sido conformado por la Segob y apenas se había integrado un recuento de sitios con fosas clandestinas, pero sin

${ }^{70}$ Laura Villafaña, "Guanajuato no tiene actualizadas cifras sobre desaparecidos", Zona Franca, 09/02/2020. Disponible en: <https://zonafranca.mx/politica-sociedad/ddhh/guanajuato-no-tiene-actualizadas-cifras-de-desaparecidos/>.

${ }^{71}$ Melissa Espinosa, "Familias de desaparecidos en Irapuato piden ayuda a Fiscalía; la respuesta: rechazo, desdén y negación”, Soy Barrio, 10/12/2019. Disponible en: <https://soybarrio.com/familias-de-desaparecidos-en-irapuato-piden-ayuda-a-fiscalia-la-respuesta-rechazo-desden-y-negacion/>.

${ }^{72}$ Laura Villafaña, "No hay fosas clandestinas en el estado: Sophia Huett", Zona Franca, 03/09/2019. Disponible en: <https://zonafranca.mx/seguridad/en-guanajuato-no-hay-fosas-solo-son-hallazgos-de-restos-oseos-sophia-huett/>. 
una metodología clara. El concepto de fosa clandestina no está contenido o definido en la citada Ley General, y, más allá de las disciplinas jurídicas, puede y debe ser tratado mediante enfoques multidisciplinarios que van de la antropología a la criminología y el derecho, de la sociología a la historia y la arqueología, por ejemplo. De manejarse conceptos estrechos o fragmentarios, el término puede prestarse a interpretaciones que no abonan a la correcta integración de los registros de fosas estatales, ni a la perspectiva de derechos humanos, base de la Ley General y la Constitución.

De mayo de 2019 a mayo de 2020 se desarrolló en Guanajuato el proceso legislativo para la aprobación, con dos años y medio de retraso respecto de lo que ordena la Ley General en Materia de Desaparición, de la Ley de Búsqueda de Personas Desaparecidas. La participación de familias víctimas indirectas, principalmente de los colectivos Justicia y Esperanza y A tu Encuentro, de organizaciones de la sociedad civil, de la academia y de personas defensoras de los derechos humanos fue bastante limitada y sólo se consiguió desde finales del mes de noviembre, gracias a la presión social y a una serie de actos públicos y peticiones por parte de colectivos de familias de Irapuato, León, Celaya, Salamanca y San Luis de la Paz, entre otras. Asimismo, no fue fácil lograr de nuevo espacios de participación ciudadana, dada la prisa que el Congreso tenía para aprobar la Ley y las resistencias a volver a abrir la discusión de puntos clave. No se consiguió establecer una modalidad de Parlamento Abierto para con las víctimas, ni que hubiera suficientes sesiones públicas de discusión, pues se estaban debatiendo al mismo tiempo la Ley de Búsqueda y la Ley de Víctimas estatales.

El día 21 de febrero de 2020, con base en un comunicado y petición pública de varios colectivos, ${ }^{73}$ que contenía exigencias y

${ }^{73}$ Colectivos A tu Encuentro, Sembrando Comunidad, Justicia y Esperanza, Buscando Desaparecidos México-Búscame, "Comunicado: Colectivos de Fa- 
sugerencias de cambios al borrador de la Ley, se realizó una única sesión de discusión, artículo por artículo, de gran parte de la propuesta legislativa, en la que participaron las Comisiones Unidas de Gobernación y Puntos Constitucionales, la de Derechos Humanos y Atención a Grupos Vulnerables y algunos voceros de familias y colectivos, expertos y defensores. ${ }^{74}$ Terminando dicha sesión, los participantes manifestaron el interés de trabajar en una definición de fosa clandestina que pudiera incluirse en la versión final de la Ley para atajar la problemática de la negación oficial de este fenómeno, por un lado, y también con el fin de dar más certidumbre sobre este tipo de sitio de hallazgo de restos o cuerpos y poder integrar adecuadamente el Registro estatal de fosas comunes y clandestinas previsto en la misma Ley. De alguna forma, el tema entró a ser parte de un campo contencioso de disputa política. Quien estableció una interlocución con asesores y colectivos fue la diputada Libia García Muñoz Ledo, de la bancada mayoritaria del Partido Acción Nacional, presidenta de la Comisión de Gobernación y Puntos Constitucionales, quien se dijo interesada en considerar una definición propuesta por académicos y colectivos.

Por lo tanto, vale la pena recuperar aquí unas propuestas definitorias que, entre marzo y mayo de 2020, tuvieron cierto impacto en el debate entre distintos actores políticos y sociales y que fueron presentadas por colectivos, académicos ${ }^{75}$ y organiza-

miliares de Personas Desaparecidas Presentan Propuestas de Metodología para Mesas de Trabajo y Plataforma Legislativa”, 14/02/2020. Disponible en: <https://desinformemonos.org/familiares-de-desaparecidos-presentan-propuestas-de-mesas-de-trabajo-y-plataforma-legislativa-en-guanajuato/>.

${ }^{74}$ Verónica Espinosa, "En Guanajuato piden eliminar la categoría 'persona no localizada' de ley sobre desaparecidos”, Proceso, 22/02/2020. Disponible en: <https://www.proceso.com.mx/618923/guanajuato-persona-no-localizada>.

${ }^{75} \mathrm{El}$ autor de este artículo estuvo involucrado en este proceso como parte del proyecto de investigación e incidencia "La desaparición de personas en Guanajuato", registrado ante la Dirección de Investigación y Posgrado de la Universidad Iberoamericana León en 2020 y apoyado por el Departamento de Ciencias Sociales y Humanidades. 
ciones internacionales, mismas que ofrecieron su experiencia en este tema y respaldaron su inclusión de la definición en la Ley. ${ }^{76}$

En un sentido amplio, diríamos "sociológico", y con fines de visibilización de las graves violaciones a derechos humanos implicadas en el hallazgo persistente de cadáveres y restos en el país, entonces, la fosa clandestina puede concebirse como cualquier sitio en el cual se enterraron, arrojaron o colocaron en un espacio en el subsuelo, total o parcialmente, uno o más cadáveres, osamenta y/o restos humanos, de manera ilegal, pudiendo presumirse el propósito de ocultar el paradero de una o más personas, dificultar o imposibilitar su localización y/o identificación, destruir evidencia, o bien, entre otras cosas, evitar que las autoridades puedan investigar o sancionar las razones y/o las modalidades de tales actos.

Si bien esta formulación, construida en un primer momento para el debate sobre la Ley de Búsqueda en Guanajuato y enviada al Congreso como propuesta inicial, es explicativa, abona a la des-

${ }^{76} \mathrm{~A}$ fin de cuentas, ninguna definición de fosa clandestina fue incorporada a la ley, pese a que, en la sesión de las comisiones unidas, ya mencionada, del 21 de febrero de 2020, los mismos congresistas habían mostrado interés hacia ello, así como las familias y los colectivos allí representados. Un logro de esa sesión fue avanzar hacia la decisión de eliminar la categoría de "persona no localizada" de la ley estatal, siendo Guanajuato, junto con la Ciudad de México y el Estado de México, una de las tres entidades que realizaron este cambio en sus legislaciones locales, garantizando así que, desde que se tenga reporte, noticia o denuncia de una desaparición, tanto la búsqueda como la investigación deberán comenzar inmediata y conjuntamente y que el registro de personas desaparecidas y no localizadas no sea utilizado, como en efecto había sucedido, para invisibilizar el fenómeno y las cifras de la desaparición.

Por otro lado, tras la primera búsqueda en terreno organizada por la Comisión Estatal de Búsqueda de Personas (operativa desde el 3 de julio de 2020 con el comisionado Héctor Díaz Esquerra) junto con autoridades federales, la fiscalía estatal y la CNB, realizada en Uriangato del 3 al 7 de agosto de 2020, los colectivos volvieron a pedir una modificación de la Ley estatal para incluir la definición de fosa clandestina y de sitio de hallazgo/de depósito. Participaron en esta primera búsqueda el Frente para la Búsqueda de Personas Desaparecidas en Guanajuato -integrado por cuatro colectivos (Buscadoras Guanajuato, Cazadores, Justicia y Esperanza, Mariposas Destellando)-, el colectivo A tu Encuentro y otros grupos de familias. 
cripción completa del fenómeno e incluye sitios de diferente tipo, ya sean naturales o artificiales, inhumaciones parciales o totales de cuerpos o restos, que estén o no del todo cubiertos u ocultos. También presenta debilidades: en su segunda parte establece la presunción de un propósito de ocultamiento que, en el momento del simple registro de un sitio y sus características durante alguna fase de la búsqueda en campo o de la investigación, podría no aparecer, no ser detectado o no ser interpretado de forma correcta, de buena o de mala fe, por quien registre o clasifique el sitio, generando algún tipo de confusión o subregistro.

Otra propuesta, respaldada por los colectivos Sembrando Comunidad, A tu Encuentro y Justicia y Esperanza, con apoyo de organizaciones nacionales y el Comité Internacional de la Cruz Roja, se articulaba en diferentes apartados e incorporaba la exigencia de rigor desde el derecho y la arqueología forense, pero con el ánimo de poder reconocer múltiples sitios y condiciones de hallazgo e integrar mejores registros, especificando las siguientes definiciones:

Sitio: Corresponde a cualquier lugar donde se han encontrado cuerpos de personas fallecidas. (Por ejemplo: cementerio, base militar, hacienda, un edificio, etc.) (Para el Código Nacional de Procedimientos Penales corresponde al Lugar de los Hechos o del hallazgo) (Artículo 227).

Punto de depósito ilegal: Un lugar específico, invariablemente incluido dentro del Sitio, en el cual se colocaron, ya sea inhumados total o parcialmente, o dispuestos, indicios, uno o más cuerpos o partes de ellos. (Por ejemplo: fosa clandestina, en superficie, cuerpos de agua, hornos, etc.).

Fosa clandestina: Tipo de punto de depósito que consiste en un espacio en el sustrato terrestre, natural o artificial, en el cual se depositaron uno o más cuerpos o partes de ellos de manera ilegal. 
Lugar de inhumación o resguardo de Personas Fallecidas No Identificadas y Personas Fallecidas Identificadas No Reclamadas: Espacio destinado por el Estado para el resguardo de las Personas Fallecidas No Identificadas y Personas Fallecidas Identificadas No Reclamadas. ${ }^{77}$

Hace poco, la Comisión Nacional de Búsqueda, en su Proyecto de Protocolo Homologado de Búsqueda, ha introducido el concepto de "contexto de hallazgo de restos humanos", que es un "sitio donde ilegalmente han sido depositados, degradados, ocultados o transportados restos humanos no arqueológicos", 78 siendo las fosas clandestinas, los pozos artesianos, las cavernas, los tiros de minas, los cuerpos de agua, los basureros, los inmuebles habitacionales y los sistemas de drenaje algunos posibles ejemplos. ${ }^{79}$ Todos estos sitios son fundamentales para analizar los patrones de ocultamiento de restos humanos, quizá relacionados con una precedente desaparición de personas, lo cual abona al esclarecimiento de la verdad, y se deberán incorporar en el Registro Nacional de Fosas Comunes y Fosas Clandestinas. En este caso la fosa clandestina se clasifica como un tipo de contexto de hallazgo y, en la versión final del Protocolo, al fin se define a raíz de la presencia de restos en cavidades en la tierra, creadas deliberadamente para ocultarlos. ${ }^{80}$ Es en ese sitio en donde se determina y evidencia la relación entre la búsqueda en campo de cuerpos y/o restos no arqueológicos de personas desaparecidas, su anterior privación de

77 Colectivos A tu Encuentro, Sembrando Comunidad, Justicia y Esperanza, "Comentarios a la Propuesta de la Ley de Búsqueda de Personas Desaparecidas en el Estado de Guanajuato", , mayo de 2020. Disponible en: <https://drive. google.com/file/d/1UTN1fc5PdGee_cBfzGUxk43Nm62e6HNx/view>.

${ }^{78}$ Comisión Nacional de Búsqueda, "Proyecto de protocolo homologado para la búsqueda de personas desaparecidas y no localizadas (versión 5/5/2020 para fortalecimiento)", p. 27.

${ }^{79}$ Ibidem, p. 27.

${ }^{80}$ Comisión Nacional de Búsqueda, "Proyecto de protocolo homologado para la búsqueda de personas desaparecidas y no localizadas (versión con cambios producto del fortalecimiento resaltados, 27/08/2020)”, p. 114. 
la libertad y de la vida, su ocultamiento ilegal y, por último, el conjunto de graves violaciones y descomposición social que son efectos y, a la vez, condiciones de posibilidad de las propias fosas.

Otra definición, más acotada para la sección de definiciones de la Ley, fue parte de una propuesta de académicos y defensores de derechos humanos en Guanajuato, respaldada por el trabajo en conjunto con la Oficina del Alto Comisionado de las Naciones Unidas para los Derechos Humanos en México y, al no haber sido incluida en el texto final, fue presentada también como reserva por parte de congresistas de oposición ante el pleno del Congreso. ${ }^{81}$ Asimismo hay una definición tanto de fosa clandestina como de "sitio de depósito", una noción más amplia que incorpora la de fosa y, a su vez, es compatible (incluso parecida o equivalente) con el concepto, ya mencionado, de "contexto de hallazgo" propuesto por la Comisión Nacional de Búsqueda. En pocas palabras, la fosa es un sitio de depósito o contexto de hallazgo particular, en el cual los restos o cuerpos se encuentran al menos en parte ocultados de modo ilegal en algún nivel de profundidad respecto de la superficie terrestre.

Sitio de depósito: cualquier sitio en el que se colocaron uno o más cuerpos o restos humanos, y que no fue específicamente determinado por las autoridades para dicho fin.

Fosa clandestina: cualquier sitio en el que se colocaron en un espacio en el subsuelo, o en el que se inhumaron, total o parcialmente, uno o más cuerpos o restos humanos, y que no fue específicamente determinado por las autoridades para dicho fin. ${ }^{82}$

\footnotetext{
${ }^{81}$ Fabrizio Lorusso, "Covid-19 no frena desapariciones. Discusión y propuesta sobre el concepto de fosa clandestina”.

${ }^{82}$ Fabrizio Lorusso y Raymundo Sandoval, "Ley de Búsqueda de Personas Desaparecidas y Ley de Víctimas en Guanajuato. ¿Qué falta?”, PopLab, 12/05/2020. Disponible en: <https://poplab.mx/article/LeydeBusquedadePersonasDesaparecidasyLeydeVictimasenGuanajuatoQuefalta>.
} 
Según esta propuesta, el Registro Estatal de Fosas Comunes y Clandestinas, previsto en la Ley, se debía nombrar "Registro Estatal de Fosas Comunes, Fosas Clandestinas y Sitios de Depósito", lo cual habría dado mayor claridad a los términos ante la opinión pública y las autoridades en el estado, y habría servido de insumo para alimentar como se debe a los correspondientes registros nacionales.

El Protocolo Homologado de Investigación para los Delitos de Desaparición Forzada y Desaparición Cometida por Particulares rige las operaciones de los ministerios públicos y las fiscalías y, aunque no las define de modo exacto y desglosado, entiende las fosas clandestinas "como inhumaciones ilegales" y como "partes de la escena del crimen". ${ }^{83}$

En compatibilidad con éste y con el ánimo de evitar que desde la definición sea involucrado un objeto que las investigaciones forenses no puedan identificar exacta y claramente, o bien, que se tengan que probar de alguna forma o fijar criterios de presunción legal sobre "los posibles fines o propósitos" del autor del crimen, se optó por proponer una definición más puntual, precisa, de fosa clandestina como propuesta para la Ley de Búsqueda de Guanajuato, pero sin sacrificar la idea de ampliar un poco la estrecha visión de la arqueología tradicional.

En este sentido la propuesta considera: 1) una pluralidad de sitios naturales y artificiales, sintetizada por la ya mencionada noción de "cualquier sitio"; 2) que tengan algún tipo de profundidad en el subsuelo o sustrato terrestre (lo cual respeta la definición tradicional o técnica de una fosa, sin especificar tamaños o niveles precisos de profundidad para que sea considerada tal); 3) que contenga cuerpos, partes o restos allí colocados, ya sea cubiertos con tierra (es decir, enterrados/inhumados), o sólo dispuestos, total o parcialmente, en el nivel del subsuelo (sin que por fuerza haya tierra o materiales encima); 4) y por último el elemento o

${ }^{83}$ CNPJ, Protocolo homologado, op. cit., p. 84.

160 / Fabrizio Lorusso 
situación de ilegalidad y/o irregularidad ("no fue determinado por las autoridades para dicho fin") y de ocultamiento, ya no como "intención", "fin" o "propósito" que habría que suponer o demostrar, sino integrado en el mismo concepto de cuerpos o restos ubicados en un "espacio en el subsuelo" (en el sustrato terrestre, o en profundidad). Éstos de por sí se encuentran total o parcialmente ocultos, no están del todo (o para nada) a la vista, y se hallan dentro de una fosa ilegal. Son entonces elementos de un espacio clandestino, o sea "oculto o semioculto" e ilegal a la vez, lo cual desde la definición propuesta permite evitar interpretaciones cambiantes sobre las formas o los "niveles" de ocultamiento "necesarios" para poder identificar como fosa clandestina un sitio de esta naturaleza. ${ }^{84}$

El Registro Estatal de Fosas Comunes y Clandestinas, según la misma propuesta, podría pasar a llamarse "Registro Estatal de Fosas Comunes, Fosas Clandestinas y Sitios de Depósito", al registrar: 1) las fosas clandestinas, arriba definidas, como una subcategoría de los sitios de depósito, mismos que entrarían en otro rubro aparte, enlistados con sus características; 2) un elenco con descripción detallada de todos los otros sitios de depósito o contextos de hallazgo y disposición de cuerpos que no son fosas clandestinas: espacios por completo superficiales con cuerpos expuestos o cubiertos con materiales naturales o artificiales de todo tipo; la vía pública; puentes, árboles o carreteras y sus orillas, entre otros. El correcto registro de éstos es fundamental para el análisis de contexto, la integración del registro estatal y nacional forense, los registros de fosas, así como para la comprensión de los fenómenos delictivos y los patrones relacionados directa e indirectamente con la desaparición de personas, los homicidios y los feminicidios en la entidad.

Por último, el desenlace del proceso legislativo en el Congreso local fue el 14 de mayo de 2020, día de la aprobación de la Ley en

${ }^{84}$ Lorusso, "Covid-19 no frena", op. cit.

Una discusión sobre el concepto de fosa clandestina y el contexto... / 161 
el pleno, en donde se descartaron tanto estas definiciones de fosas clandestinas como las diez reservas legislativas presentadas por diputadas de la oposición (Partido Verde y Morena) y respaldadas por colectivos de víctimas, expertos y sociedad civil. ${ }^{85}$

\section{Conclusiones}

El caso del estado de Guanajuato muestra que existe una disputa política y social ${ }^{86}$ en torno a la definición de fosa clandestina, a la búsqueda de las personas desaparecidas y a la publicación de registros e información precisa acerca de ellas y de las fosas clandestinas, así como de otros sitios de depósito o de hallazgo de restos humanos y de cuerpos que allí se encuentran. Recuperar y adaptar las mejores prácticas nacionales e internacionales al respecto es una tarea urgente que puede ser clave en la garantía del derecho a la verdad y la justicia, y un mensaje contundente contra la impunidad. Guanajuato es una de las cinco entidades que, al menos hasta agosto de 2020, declaraba de manera oficial no tener ninguna fosa clandestina en su territorio, pese a que registros hemerográficos y bases de datos alternativas, elaboradas por colectivos y académicos, demostraran lo contrario, con independencia de la definición, más o menos "técnica" o restrictiva, que se pretendiera adoptar.

Por otro lado, hasta junio de 2020, no se habían publicado datos oficiales sobre las personas desaparecidas en el estado, destacando así la opacidad y la indolencia. Como ya mencioné, a mediados de julio el dato finalmente fue difundido como pura cifra, pero no venía acompañado de un verdadero registro con

${ }^{85}$ Raymundo Sandoval, "Las reservas de la Ley de Búsqueda", PopLab, 17/05/2020. Disponible en: <https://poplab.mx/column/Laboratoriodelosderechos/LasreservasdelaLeydeBusqueda>.

${ }^{86}$ Laura Villafaña, "Fosa clandestina es hallada en Guanajuato; familias exigen que los incluyan en búsquedas", Sin Embargo, 30/05/2020. Disponible en: $<$ https://www.sinembargo.mx/30-05-2020/3795767>. 
información relevante. La invisibilización o la negación de la violencia en general, de los homicidios hasta cuando fue posible $y$, hace poco tiempo, también de las desapariciones y de las fosas clandestinas, ha sido un aspecto insoslayable de la dinámica política y de la narrativa oficial sobre el conflicto armado, la crisis de derechos humanos y la descomposición del tejido social que vive Guanajuato. En lugar de aprovechar la experiencia y las enseñanzas de estados del resto del país, que han conocido con anterioridad las dinámicas de la violencia y los dispositivos de la desaparición de personas, se está apostando más bien a prolongar la fase de la negación y la minimización, creando las condiciones para mayores distancias y desconfianza entre la ciudadanía y las víctimas, por un lado, y con las autoridades, como la fiscalía, el propio gobierno y el congreso, que están al frente en estos procesos. ${ }^{87} \mathrm{La}$ disputa sobre las fosas clandestinas tiene que ver, asimismo, con el uso de este término en México y su evitación en Guanajuato. Hablar de las fosas prende inmediatamente una alerta, cuestiona a los poderes que las permiten u ocultan, y nos remite al imaginario terrible de la noche de violencias que vivimos. Despierta la visión de los límites civilizatorios que se han roto en Colinas de Santa Fe, Veracruz; en San Fernando, Tamaulipas; en Tetelcingo, Morelos; o en los cerros de Iguala, Guerrero, entre otros espacios de excepción e impunidad en donde los miles de "otros desaparecidos" del país reivindican su presencia en la ausencia, evidenciada por el dolor común de sus deudos y por las búsquedas colectivas que destapan el horror y la complicidad de las autoridades con este presente doloroso.

El proceso de discusión y aprobación de la Ley de Búsqueda de Personas Desaparecidas en Guanajuato representa otra muestra de la dificultad de diálogo y de comprensión profunda, efectiva,

${ }^{87}$ David Saucedo, "Los desaparecidos del narco. Guanajuato podría aprovechar hoja de ruta y evitar tortuoso sendero de otras entidades", PopLab, 02/12/2019. Disponible en: <https://poplab.mx/article/LosdesaparecidosdelnarcoGuanajuatopodriaaprovecharhojaderutayevitartortuososenderodeotrasentidades $>$. 
del enfoque de derechos y de los derechos humanos en general por parte de los poderes del estado, renuentes a incorporar a las familias, los colectivos y la sociedad civil de manera adecuada en el debate y en las decisiones, aunque así lo prevean la Ley General de Víctimas y la de Materia de Desaparición. Aun así, ha habido avances, la apertura de diálogos y espacios que tan sólo en 2019 no existían y no se reivindicaban por parte de los buscadores. El interés manifestado por congresistas en recibir propuestas de definición de fosa clandestina e impulsar, también de esta forma, la mejora de los registros, quedó en las intenciones, como varios otros cambios posibles que fueron descartados, generando decepción entre las familias de personas desaparecidas en la entidad. No obstante, varios temas fueron colocados en la agenda de los medios y en el repertorio de exigencias y conocimientos de los colectivos, que pueden seguir aprovechándolos.

El registro de fosas clandestinas estatal, para agosto de 2020, aún no había sido creado. Queda el riesgo de que se maneje bajo criterios restrictivos $\mathrm{o}$, inclusive, potencialmente discrecionales con el resultado de ocultar o redimensionar este fenómeno, que desde luego es de alto impacto para la opinión pública y la sociedad. Al contrario, la literatura especializada de las últimas décadas, junto con la experiencia de campo de los colectivos buscadores, ha mostrado la tendencia a darle mayores alcances a su definición e interpretación, considerando de alguna manera los "entierros superficiales", así como los profundos, desde luego, y tomando en cuenta las inhumaciones ilegales de tipo individual y colectivo, natural (como cañadas, depresiones dentro de ríos secos) y artificial (hoyos en el terreno, casas de seguridad con excavaciones) y hasta fosas que no son en sí enterramientos o excavaciones, sino sitios de disposición de restos humanos de todo tipo que manifiestan el fin de esconderlos (por ejemplo, cuerpos cubiertos de madera, piedras o follaje, o sólo semienterrados).

La Fiscalía General del Estado ha privilegiado un discurso ambiguo y definiciones de fosa clandestina hasta cierto punto 
estrechas, técnicas, según el marco de la antropología tradicional, las que no se han correspondido con las de la Secretaría de Gobernación y de la CNDH, por mencionar dos ejemplos. Mucho menos ha habido coincidencia o intercambio con la praxis y el conocimiento proporcionado por los movimientos de buscadores de personas desaparecidas en México en sus hallazgos sobre las fosas clandestinas en el país.

En el caso de la búsqueda de las personas desaparecidas, así como del debate que ha habido sobre la Ley estatal, ante la negativa de reconocer la presencia de fosas clandestinas como espacios y contextos de graves violaciones a derechos humanos, lo cual implica también una responsabilidad por parte de las autoridades, el hecho relevante es que se están hallando cada vez más restos humanos abandonados en entierros ilegales de todo tipo, que en muchos casos son fosas clandestinas que se deberían registrar con oportunidad, evitando ocultarlas y buscando la verdad. La discusión sobre una posible definición, como las propuestas por colectivos, organizaciones y académicos, trata de dar cuenta de una realidad concreta sobre las fosas en Guanajuato y México, un contexto social e históricamente ubicado, en el cual hacen falta amplias e inclusivas definiciones tipológicas, que resalten las violaciones a derechos humanos implicadas en la misma existencia y naturaleza del fenómeno, así como la necesidad de contar con instituciones abiertas para con las víctimas y la sociedad civil. 氐

\section{Bibliografía}

Aguirre, Arturo. Nuestro espacio doliente. Reiteraciones para pensar en el México contemporáneo, Puebla, México, Afínita Ed./Buap, 2016.

Alexander, Michael Benjamin. "The Forensic Application of Soil: Clandestine Graves and Human Remains Detection Dogs", Disertación para obtener grado de doctorado en Ciencias del Suelo, Texas A\&M University, diciembre de 2014. Disponible en: <https://oaktrust.library.tamu. edu/bitstream/handle/1969.1/154181/ALEXANDER-DISSERTATION-2014. pdf>.

Una discusión sobre el concepto de fosa clandestina y el contexto... / 165 
Ameglio, Pietro. “'No buscamos huesos, buscamos tesoros': V brigada de Búsqueda de Personas Desaparecidas en Veracruz", Desinformémonos, 14/02/2020. Disponible en: <https://desinformemonos.org/no-buscamos-huesos-buscamos-tesoros-v-brigada-nacional-de-busqueda-de-personas-desaparecidas-en-veracruz/>.

Cavarero, Adriana. Horrorismo. Nombrando la violencia contemporánea, Barcelona, Anthropos, 2009.

CMDpdh (Comisión Mexicana para la Defensa y Promoción de los Derechos Humanos). Crimenes de lesa humanidad en México en el marco de la lucha contra las drogas, México, СмDPDH/Idheas, 2018. Disponible en: <http://www.cmdpdh.org/publicaciones-pdf/cmdpdh-epu-crimenes-de-lesa-humanidad-en-el-marco-de-la-lucha-contra-las-drogas.pdf>

Comisión Nacional de Búsqueda de Personas Desaparecidas (CNB). "Proyecto de protocolo homologado para la búsqueda de personas desaparecidas y no localizadas (versión con cambios producto del fortalecimiento resaltados, 27/08/2020)", Segob, 2020, México. Disponible en: <https:// ita.calameo.com/read/006323916e4b0eef057ad>.

"Búsqueda, Identificación y registro de Personas desaparecidas (corte al 13 de julio de 2020)", México, CNB, 13/07/2020. Disponible en: <http:// www.alejandroencinas.mx/wp-content/uploads/2020/07/Presentacio\%CC\%81nCNB-13-de-julio-2020-final.pdf>.

. "Informe sobre fosas clandestinas y registro nacional de personas desaparecidas y no localizadas", México, CNB, 06/01/2020. Disponible en: <https://www.gob.mx/cms/uploads/attachment/file/535387/ CNB_6_enero_2020_conferencia_prensa.pdf.pdf>.

- "Proyecto de protocolo homologado para la búsqueda de personas desaparecidas y no localizadas (versión 5/5/2020 para fortalecimiento)”, México, Segob, 2020. Disponible en: <https://www.gob.mx/cms/ uploads/attachment/file/551671/PPHB_Versi_n_para_fortalecimiento_5may2020_2_.pdf>; y <https://www.gob.mx/cnb>.

. "Proyecto de protocolo homologado para la búsqueda de personas desaparecidas y no localizadas (versión con cambios producto del fortalecimiento resaltados, 27/08/2020)".

Comisión Nacional de los Derechos Humanos (CNDH). "Informe Especial sobre Desaparición de Personas y Fosas Clandestinas en México", México, CNDH, 2016. Disponible en: <http://informe.cndh.org.mx/ uploads/menu/30100/InformeEspecial_Desapariciondepersonasyfosasclandestinas.pdf>.

\section{I66 / Fabrizio Lorusso}


"Recomendación No. 48/2016, Sobre el caso de la violación al derecho de acceso a la justicia en la modalidad de inadecuada procuración de justicia y violación al derecho a la verdad, relacionado con la irregular inhumación de 119 cadáveres en la comunidad de Tetelcingo, Municipio de Cuautla”, 2016. Disponible en: <https://www.cndh.org. $\mathrm{mx} / \mathrm{sites} / \mathrm{all} / \mathrm{doc} /$ Recomendaciones/2016/Rec_2016_048.pdf>.

Conferencia Nacional de Procuración de Justicia (CNPJ). Protocolo homologado de investigación para los delitos de desaparición forzada y desaparición cometida por particulares, México, CNPJ, 2019.

Estévez, Ariadna. "El dispositivo necropolítico de producción y administración de la migración forzada en la frontera Estados Unidos-México", Estudios Fronterizos, 19, 10, 2018, pp. 1-18. https://doi.org/10.21670/ ref. 1810010

González Núnez, Denise, Jorge Ruiz Reyes, Lucía Guadalupe Chávez Vargas y José Antonio Guevara Bermúdez (coords.). Violencia y terror. Hallazgos sobre fosas clandestinas en México, México, Universidad Iberoamericana, 2017. Disponible en: <https://ibero.mx/files/2019/violencia-y-terror.pdf $>$.

Hays, W. Morgan. "Florida's Clandestine Graves: An Anthropological Perspective of the Dead", Tesis para obtener el grado de Maestro en Antropología, Florida State University, College of Arts and Science, Tallahasse FL, primavera de 2008.

Hochrein, Michael J. "Buried Crime Scene Evidence: The Application of Forensic Geotaphonomy in Forensic Archaeology", en Stimson y Mertz (eds.), Forensic Dentistry (Cap. 5), Boca Raton FL, CRC Press, 2002, pp. 83-98.

Huffschmid, Anne. "Huesos y humanidad. Antropología forense y su poder constituyente ante la desaparición forzada", Athenea Digital, 15(3), 2015, pp. 195-214. Disponible en: <http://dx.doi.org/10.5565/rev/ athenea.1565>.

- "Paisajes forenses: sobre cómo mirar, leer y narrar las fosas intervenidas de nuestro tiempo", en Arturo Aguirre y Juan Carlos Ayala (coords.), Tiempos sombrios: violencia en el México contemporáneo, Buenos Aires, Biblos, 2019, pp. 39-70.

Jessee, Erin y Mark Skinner. "A Typology of Mass Grave and Mass Grave-Related Sites”, Forensic Science International, 152(1), 2005, pp. 5559. https://doi.org/10.1016/j.forsciint.2005.02.031

Jugo, Admir y Sari Wastell. "Disassembling the Pieces, Reassembling the Social: The Forensic and Political Lives of Secondary Mass Graves in

Una discusión sobre el concepto de fosa clandestina y el contexto... / 167 
Bosnia and Herzegovina”, en Elisabeth Gessat-Anstett, Elisabeth Anstett y Jean-Marc Dreyfus (eds.), Human Remains and Mass Violence: Methodological Approaches, Manchester, Manchester University Press, 2014. Disponible en: <https://www.manchesteropenhive.com/view/97 81526125019/9781526125019.00013.xml>.

Komar, Debra. "Patterns of Mortuary Practice Associated with Genocide Implications for Archaeological Research", Current Anthropology, 49 (1), 2008, pp. 123-133.

Lorusso, Fabrizio, "Covid-19 no frena desapariciones. Discusión y propuesta sobre el concepto de fosa clandestina”, Uia León, 01/05/2020. Disponible en: <https://www.leon.uia.mx/noticias/articulo.cfm?Liga=COVID-19-no-frena-desapariciones>.

Mant, A. K. "Knowledge Acquired from Post-War Exhumations", en A. Boddington, Garland y Janaway (eds.), Death, Decay and Reconstruction: Approaches to Archaeology and Forensic Science, Manchester, Manchester University Press, 1987, pp. 65-78.

Naciones Unidas. UN Doc E/CN.4/1993/50. Situación de los derechos humanos en el territorio de la antigua Yugoslavia. Informe sobre la situación de los derechos humanos en el territorio de la antigua Yugoslavia presentado por el Sr. Tadeusz Mazowiecki, Relator Especial de la Comisión de Derechos Humanos, para dar efecto a la resolución 1992/S-1/1 adoptada por la Comisión el 14 de agosto de 1992, Anexo I: Informe del Relator Especial sobre ejecuciones extrajudiciales, sumarias o arbitrarias, acerca de su misión para determinar la veracidad de las informaciones sobre la existencia de fosas comunes, efectuada del 15 al 20 de diciembre de 1992, onu, 1993. Disponible en: <https://digitallibrary.un.org/ record/168436/files/A_48_92\%26S_25341-ES.pdf>.

ONU-Derechos Humanos (2020). "ONU-DH: a dos años de su entrada en vigor, es necesario redoblar esfuerzos en la implementación de la ley de desaparición de personas". Disponible en: <http://www.onu.org.mx/ onu-dh-a-dos-anos-de-su-entrada-en-vigor-es-necesario-redoblar-esfuerzos-en-la-implementacion-de-la-ley-sobre-desaparicion-de-personas/>.

Open Society Justice Iniciative. Atrocidades innegables: confrontando crimenes de lesa humanidad en México, Nueva York, Open Society Foundations, 2016. Disponible en: <https://www.justiceinitiative.org/uploads/ 5d386d17-57aa-4b74-b896-43883af55574/undeniable-atrocities-esp2nd-edition.pdf>.

168 / Fabrizio Lorusso 
Paley, Dawn Marie. Capitalismo antidrogas. Una guerra contra el pueblo, México, Libertad Bajo Palabra, 2018.

Perera, C. y C. Briggs. "Guidelines for the Effective Conduct of Mass Burials Following Mass Disasters: post-Asian Tsunami Disaster Experience in Retrospect", Forensic Science, Medicine and Pathology, 4(1), pp. 1-8.

Pringle, J.K., J. Jervis, J. P. Cassella y N. J.Cassidy. "Time-Laps Geophisycal Investigations over a Simulated Urban Clandestine Grave”, Journal of Forensic Science, v. 53, n. 6, nov. 2008, pp. 1405-1416.

Procuraduría General de la República (PGR). Protocolo para el tratamiento y la identificación forense, México, PGR, 2015.

Reguillo, Rossana. "De las violencias: caligrafía y gramática del horror", Desacatos, n. 40, México, sep.-dic. 2012, pp. 33-36. https://doi. org/10.29340/40.254

Robben, Antonius C. G. M. "Exhumations, Territoriality, and Necropolitics in Chile and Argentina”, en Francisco Ferrándiz y M. Robben, Necropolitics: Mass Graves and Exhumations in the Age of Human Rights, Filadelfia, University of Pennsylvania Press, 2015.

Robledo, Carolina. "Peinar la historia a contrapelo: reflexiones en torno a la búsqueda y exhumación de fosas comunes en México", Encartes, n. 3, marzo-agosto 2019, pp. 13-42.

Rosenblatt, Adam. Digging for the Disappeared. Forensic Science after Atrocity, Stanford, Stanford University Press, 2015.

Ruiz Reyes, Jorge, Fabrizio Lorusso y Óscar Elton Susarrey. Informe sobre la situación de las fosas clandestinas en Guanajuato (2009 a julio de 2020), México, Uia Ciudad de México/Uia León/Data Cívica, 2020.

Ruiz Reyes, Jorge. "Fosas clandestinas y su relación con crímenes de lesa humanidad. Propuesta metodológica para la documentación de casos que determinen responsabilidad penal internacional en México", Historia y Grafia, 52, ene-jun 2019, pp. 97-128. Disponible en: <http://www.scielo.org.mx/pdf/hg/n52/1405-0927-hg-52-97.pdf>.

Schmitt, Stefan. "Mass Graves and the Collection of Forensic Evidence: Genocide, War Crimes and Crimes against Humanity", en William D. Haglund y Marcella H. Sorg (eds.), Advances in Forensic Taphonomy, Boca Raton FL, CRC Press, 2001, pp. 277-292.

Secretaría de Gobernación (Segob). "Reporte: Fosas clandestinas diciembre 2018 - 13 de mayo 2019”, México, Segob, 2019. Disponible en: <http://www.alejandroencinas.mx/wp-content/uploads/2019/05/Fosas_13mayo19-ok.pdf>.

Una discusión sobre el concepto de fosa clandestina y el contexto... / 169 
unami/ohchr (un Assistance Mission for Iraq, Office of the High Commissioner for Human Rights), (2018). Unearthing Atrocities: Mass Graves in territory formerly controlled by ISIL, Ginebra, Naciones Unidas. Disponible en: <https://reliefweb.int/sites/reliefweb.int/files/resources/ UNAMI_Report_on_Mass_Graves4Nov2018_EN.pdf>.

Universiteit Leiden. The Situation of Drug-Related Violence in Mexico from 2006-2017: A Non-International Armed Conflict?, Leiden IHL Clinic Report Series n. 28, Leiden (Países Bajos), Universiteit Leiden, 2018.

Valencia, Sayak. Capitalismo gore. Control económico, violencia y narcopoder, México, Paidós, 2016. 